\title{
O FENÔMENO DA GLOBALIZAÇÃO: UMA BREVE ANÁLISE A PARTIR DA AMÉRICA LATINA
}

Renato Zerbini Ribeiro Leão ${ }^{1}$

Os últimos vinte anos do século $\mathrm{XX}$ e os primeiros quatro anos do século XXI representam para a América Latina um período de busca intensa pelo desenvolvimento nos campos econômico e social, e, de afirmação na área cultural.

O cenário econômico e social pautou-se pela constante tentativa de estabilização estrutural de suas sociedades marcadas de um lado pela presença ou resquícios dos regimes autoritários ou ditatoriais e de outro pelas constantes crises econômicas mundiais. Na esfera cultural, por sua vez, incrementou-se o debate acerca da verdadeira identidade latino-americana. $^{2}$

A discussão é permeada por um vultuoso fenômeno detentor de um papel quase que protagônico no campo de estudos das Relações Internacionais: a Globalização. ${ }^{3}$ Basicamente, o termo sugere a idéia de que uma sociedade coesa, fechada e uma economia doméstica já não se sustentam ante o avance de uma economia e uma

\footnotetext{
${ }^{1}$ Advogado. Bacharel e Mestre em Relações Internacionais pela Universidade de Brasília. Diretor Presidente do Centro de Proteção Internacional de Direitos Humanos. Coordenador do Curso de Relações Internacionais do Centro Universitário de Brasília - UniCEUB.

${ }^{2}$ IBÁÑEZ, Jorge Larraín. Modernidad, razón e identidad en America Latina. Chile: Editorial Andres Bello, capítulo 3, 1996.

${ }^{3}$ A "Globalização" é um fenômeno que envolve muitas matizes para sua compreensão, portanto, um objeto de estudo muito complexo. O objetivo desta tese não é esgotar todos os conceitos pertinentes ao seu universo teórico(os próprios estudiosos da matéria têm opiniões divergentes), mas sim, apresentá-los de maneira a clarificar o propósito da dissertação.
}

Universitas - Relações Int., Brasília, v. 2, n.1, p. 103-115, jan./jun. 2004 
sociedade efetivamente globais, sendo a vida cotidiana dependente e movida por "forças globais". ${ }^{4}$

A globalização tem, de acordo a distintos autores estudados ${ }^{5}$, certos elementos comuns que ajudam a sua compreensão, tais como o domínio das finanças sobre a produção; a importância do conhecimento; o incremento da tecnologia; a influência das corporações multinacionais; e a erosão do estado nacional.

O domínio das finanças sobre a produção significa que a acumulação de capital assume o norte orientador e o fim de todo o processo em discussão. Ou seja, o cenário da globalização é marcado pela crescente importância da estrutura financeira e da criação, em escala planetária, do crédito. ${ }^{6}$

A importância do conhecimento é pautada no sentido de este ser um importante fator da produção. As indústrias devem ser estruturadas no conhecimento, já que se tornam simultaneamente diversificadas e especializadas, portanto, somente sobreviverão aquelas capazes de desenvolver produtos pautados na qualidade, tecnologia de ponta e menor custo para o consumidor. Além disso, o conhecimento traz consigo a característica de abrir as fronteiras de qualquer país, ou seja, o conhecimento é o visto de entrada universal para qualquer localidade do planeta, pois todo Estado ou governante deseja estar próximo das fontes detentoras do conhecimento.

A tecnologia é pensada a partir da crescente dependência da inovação tecnológica e do alto risco do atraso tecnológico. ${ }^{7}$ Há uma ideologia universalmente predominante de que aqueles países fora da

\footnotetext{
${ }^{4}$ A expressão "forças globais" é utilizada pelo autor BONEFELD, Werner. Las políticas de la globalización: ideología y crítica. In Globalización - Revista Web Mensual de Economía, Sociedad y Cultura - Editor: Federico García Morales, julio de 1998, endereço: www.rcci.net/globalización.

${ }^{5}$ Anthony Giddens, Peter Drucker, Paul Hirst, Susan Strange, Grahame Thompson, dentre outros.

${ }^{6}$ Segundo o Relatório de Desenvolvimento Humano de 1999, do Programa das Nações Unidas para o Desenvolvimento, mais de U\$ 1.5 trilhões são diariamente trocados em moeda corrente, e perto de $50 \%$ dos bens e serviços produzidos anualmente são comercializados.

${ }^{7} \mathrm{O}$ processo da globalização é marcado, o que é facilmente verificável, por um alto componente tecnológico, que inclui, dentre outros exemplos, a automação, o uso de robôs e da robótica, a fibra ótica, a comunicação por satélite e a internet.
}

Universitas - Relações Int., Brasília, v. 2, n.1, p. 103-115, jan./jun. 2004 
corrida tecnológica estão fadados a eterna dependência políticoeconômica.

Há ainda um outro aspecto tênue e perigoso, relacionado ao processo de globalização e à revolução tecnológica ocorrida no setor da informação, que está vinculado ao aparecimento do conceito de exclusão que é "a elevação das aspirações de consumo de grande parte da população mundial. O encurtamento das distâncias entre os diversos países do mundo e a exacerbação da mídia global fizeram com que o modo de vida das sociedades de consumo ocidentais, apesar de não estar acessível a todos, nem mesmo nos países ricos, fosse tomado como padrão." 8

A influência das corporações multinacionais dá-se porque estas "atravessam todas as dimensões econômicas e de um lugar para outro, atuando dentro de sociedades formalmente organizadas como Estados." Essa mobilidade "gera um menor compromisso com os países que abrigam suas atividades, o que aumenta seu poder de barganha vis-à-vis os Estados. Por outro lado, a necessidade de elevar as competitividades sistêmicas nacionais para garantir a sobrevivência nesse mundo mais integrado acrescenta restrições para a obtenção de recursos tributários adicionais. O processo de globalização, por essas e outras vias, constrange o poder dos Estados, restringindo sua capacidade de operar seus principais instrumentos discricionários."10

A erosão do estado-nacional é explicada pela força que assume atores como as corporações multinacionais (algumas mais influentes que muitos Estados), a paulatina retirada do estado-nacional como poder de regulação, a "globalização" do poder político na forma de uma estrutura de autoridade plural associada (ONU, G8), gerando uma maior incerteza reguladora institucional global e socavando os sistemas democráticos nacionais de controle e de regulação. Enfim, o

\footnotetext{
${ }^{8}$ DUPAS, Gilberto. Economia Global e Exclusão Social: Pobreza, Emprego, Estado e o Futuro do Capitalismo. Editora Paz e Terra, São Paulo, SP, 1999. p. 17.

${ }^{9}$ BENAYON, Adriano. Globalização versus Desenvolvimento. LGE Editora, Brasília. D.F., 1998. P. 17.

${ }^{10}$ DUPAS, Gilberto. op. cit. p. 14.
}

Universitas - Relações Int., Brasília, v. 2, n.1, p. 103-115, jan./jun. 2004 
desenvolvimento conduzido pela globalização da produção, do conhecimento e das finanças. ${ }^{11}$

Tais características, que ilustram a nova liberdade do capital, forma de controle regulador nacional e de responsabilidade democrática, assinalam para um incremento da destruição ecológica, da fragmentação social e da pobreza.

As estimativas atuais coincidem em assinalar e indicar a mais de $50 \%$ da população total da América Latina por debaixo da linha de pobreza. Como se não bastasse, não só aumenta o número de pobres em termos absolutos e relativos (configuram até o $80 \%$ da população em diversos países da região) senão que existe um nítido fenômeno de descenso do nível qualitativo da pobreza. Os pobres dos anos 90 são ainda mais pobres que os dos anos 80 . O estrato da pobreza que vem crescendo mais aceleradamente é os dos "pobres extremos". Trata-se de famílias que ainda destinando todos seus ingressos exclusivamente a consumir alimentos, não alcançam a comprar o mínimo de proteínas e calorias que se requerem para sobreviver. ${ }^{12}$

De acordo com os dados da CEPAL, no início da década de noventa havia cerca de 196 milhões de pessoas submetidas a situações de pobreza e indigência na América Latina: cerca de 84 milhões a mais do que em 1970 e 60 milhões além dos que existiam no início da década de oitenta (embora entre 1970 e 1980 tenha havido uma pequena diminuição relativa de $42 \%$ a $41 \%$ ). Do total existente no início de noventa, perto de 93,5 milhões viviam em condições de indigência. ${ }^{13}$

\footnotetext{
${ }^{11}$ STRANGE, Suzan. Political Economy and International Relations. pp. 155-174 in BOOTH, Ken \& SMITH, Steve (orgs.). International relations theory today. University Park, Penn State University, 1995.

${ }^{12} \mathrm{Os}$ dados refridos podem ser compravados in KLIKSBERG, Bernardo. Coordenador Acadêmico, Instituto Interamericano para o Desenvolvimento Social (INDES), Banco Interamericano de Desenvolvimento (BID), Washington, EUA, in La Situación Social de America Latina, 1998.

${ }^{13}$ VENTURA DIAS, Viviane. Diretora do Escritório da Comissão Econômica para América Latina (CEPAL) no Brasil. A CEPAL e os direitos econômicos, sociais e culturais in A INCORPORAÇÃO DAS NORMAS INTERNACIONAIS DE PROTEÇÃO DOS DIREITOS HUMANOS NO DIREITO BRASILEIRO. IIDH, CICV, ACNUR e CUE, San José, Costa Rica, 1996. P.665.
}

Universitas - Relações Int., Brasília, v. 2, n.1, p. 103-115, jan./jun. 2004 
O fato é que o cenário global é atualmente dominado pelo fenômeno da "globalização". À luz do estudo teórico das Relações Internacionais e dos parâmetros da globalização, o mundo atual poderia ser entendido, minimamente, sob as seguintes premissas:

ß É necessário entender o contexto global dentro do qual o Estado e outros atores interagem. O Sistema Capitalista Mundial deveria ser o ponto inicial de análise.

B É importante a análise histórica para compreender o sistema internacional.

ß É suposto a existência de mecanismos particulares de denominação, os quais previnem os países em desenvolvimento de desenvolverem-se e contribuem para um desenvolvimento mundial desigual.

ß É suposto que os fatores econômicos são essenciais para explicar a evolução e o funcionamento do Sistema Capitalista Mundial e a condição de subordinação dos países em desenvolvimento.

Interpretar a globalização a partir de uma "lógica totalizante"14, na suposição de que se trata de um processo consensual, geral e total não é correto. Em um puro exercício de idéias, toma-se como ponto de análise o fato de que, em termos macro, na economia e na sociedade o processo de globalização ainda está longe de ser compartido, pelo contrário, as taxas de desigualdades sociais e econômicas tornam-se cada vez mais avassaladoras ${ }^{15}$, e as informações relativas a esta questão encontram-se controversas e discutíveis.

A idéia da globalização é destacada nos cenários político, econômico e em grande parte da academia por uma verdadeira conspiração acerca de sua presença e importância. A sociedade deparase com uma avalanche de conceitos, informações e teses difíceis de

${ }^{14} \mathrm{O}$ conceito "lógica totalizante" poderá ser melhor aprofundado no texto "Globalização, sustentabilidade e governabilidade democrática no Brasil", de Eduardo Viola e Alejandro Olivieri in Trindade, A.A.C. e Castro, M. (orgs.), a sociedade democrática no final do século, Coleção Relações Internacionais, Paralelo 15, 1997.

${ }^{15}$ Conferir em CEPAL, Panorama Latino-Americano 1997 e Relatório de Desenvolvimento Humano do PNUD 1999.

Universitas - Relações Int., Brasília, v. 2, n.1, p. 103-115, jan./jun. 2004 
serem absorvidas, portanto, digerindo-as como algo incontestável e imutável. Poucos alertam para o fato de que a pobreza e a miséria avançam em escala descomunal por todo o globo, sobretudo, América Latina, África e Ásia.

Soma-se a discussão o fato de que a mobilidade do capital não vem gerando uma transferência significativa de investimentos e de empregos dos países desenvolvidos para aqueles que ainda não o são. Pelo contrário, o investimento externo direto é altamente concentrado nas economias industriais avançadas.

Noam Chomsky sublinha duas conseqüências importantes na globalização. A primeira é a extensão do modelo do "terceiro mundo" a países industrializados, ou seja, no "terceiro mundo" a sociedade está dividida em dois segmentos - um de extrema riqueza e privilégio, e outro de imensa miséria e desespero, formado por pessoas inúteis, dispensáveis. A segunda refere-se a coalizão, ao longo da história, das estruturas de governo em torno de outras formas de poder atualmente, basicamente em torno do poder econômico-. Em suas palavras "onde existem economias nacionais, existem Estados nacionais. Agora temos uma economia internacional e estamos avançando rumo a um Estado internacional - o que significa, por fim, um executivo internacional." 16

Os estudos das relações internacionais revelam que há uma reciprocidade entre comércio e desenvolvimento econômico. Existe também uma polêmica sobre esta relação; é um debate ainda não concluído, entretanto no qual, os Estados transmitem a idéia de que o desenvolvimento é o forte objetivo de todos eles. O papel do comércio como propulsor do desenvolvimento tem no momento histórico, nas características sociais e culturais dos países, nos produtos que se exportam, na resistência às mudanças, na forma como a produção está organizada (ou seja, as condições de produção/articulação do setor de exportação com o resto da economia), seus principais elementos que devem ser levados em consideração para este fim.

${ }^{16}$ CHOMSKY, Noam. A Minoria Próspera e a Multidão Inquieta.; tradução Mary Grace Fighiera Perpétuo. $2^{\circ}$ ed. Brasília. Editora Universidade de Brasília, 1997, pp. 13-14.

Universitas - Relações Int., Brasília, v. 2, n.1, p. 103-115, jan./jun. 2004 
Tomando como parâmetros as realidades política e econômica vivenciadas diariamente, a globalização, até então, é um fenômeno atual e incontestável. Aqueles que podem, têm a sua disposição tudo o que é produzido em qualquer parte do planeta, desfrutando o máximo da tecnologia contemporânea. Por outro lado, os que não podem vêmse cada vez mais distantes não só desse processo produtivoconsumista, como também, das características que os enquadrariam como seres humanos sob as lindes desse modelo.

O modelo político e econômico impulsado por alguns dos Estados atuais, ainda que seja um "novo arranjo" da estrutura do poder mundial, requer uma sociedade homogeneamente estruturada para seu máximo desempenho e aproveitamento.

Entretanto, é impossível para muitos Estados falar sobre desenvolvimento nacional com uma porcentagem tão significativa da população carregada de usos e costumes tão distintos dos "exigidos" pela nova ordem mundial. Neste sentido, uma questão de prioridade nacional seria a incorporação de qualquer forma de cultura distinta aos padrões tradicionais ou a eliminação de tudo que pudesse ser prejudicial às pretensões do Estado ante a "Globalização".

A ordem legal estabelecida dentro das distintas fronteiras do mundo é um caminho para a solidificação, criação e questionamento da identidade nacional. Talvez um dos desafios da sociedade atual seja de como transformar a identidade da nação através da mudança de um governo excludente a um sistema que inclua, para a construção de um estado verdadeiramente pluricultural e multiétnico ${ }^{17}$. Um objetivo que não é nada fácil sob os parâmetros da nova ordem mundial que não admite variantes profundas no cultural e social para a construção de uma "nação desenvolvida".

Não se quer dizer com isso que hoje em dia, sob o ritmo da globalização, seria impossível compatibilizar o desenvolvimento do Estado-Nação com respeito às características dos costumes de outros povos pertencentes a esta mesma nação. Sim, ressalta-se que para chegar onde estão atualmente, muitos dos Estados política e economicamente influentes destruíram culturas distintas das que lhes

17 Ler Rachel Sieder, "Derecho Consuetudinario y Transición Democrática en Guatemala", FLACSO, Guatemala, 1996.

Universitas - Relações Int., Brasília, v. 2, n.1, p. 103-115, jan./jun. 2004 
convinham para o logro efetivo de seus planos; e estrategicamente, para os que ainda estão buscando o seu desenvolvimento e estabilização é muito mais fácil trabalhar sob os mesmos parâmetros culturais. Entretanto, como bem afirma Mike Featherstone:

“(...) dependendo da prioridade que se dá ao projeto de formação da nação e aos recursos de que o Estado-Nação dispõe, será possível reiventar memórias, tradições e práticas com as quais resistir, canalizar ou controlar a penetração do mercado.(...)

(...)Necessitamos de um conceito mais nuançado e elaborado de modernidade cultural, que se situa além dos conceitos eurocêntricos sobre os efeitos homogeneizantes da industrialização, da urbanização e da burocratização. Requer-se um conceito mais global do moderno, que, em vez de preocupar-se com as seqüências históricas de transições da tradição para a modernidade e pós-modernidade, focalize a dimensão espacial e o relacionamento geográfico entre o centro e a periferia, nos quais as primeiras sociedades multirraciais e multiculturais se encontravam na periferia, e não no centro. A diversidade cultural, o sincretismo e o deslocamento ocorreram inicialmente lá.(...)" ${ }^{\prime 18}$

A idéia de crescimento pleno e integral de um país em desenvolvimento no qual se nota uma convergência de culturas distintas na formação de seu povo deverá passar necessariamente em um primeiro plano pela educação, respeito e conhecimento de sua população. Esta idéia é gerada a partir da premissa de que o êxito de um determinado país sob as diretrizes de um modelo político e econômico qualquer, fundamenta-se em uma sociedade compactamente estruturada.

Dever-se-ia buscar um desenvolvimento que se fundamenta na sustentabilidade, partindo do princípio de que desenvolvimento sustentável é um processo de mudança progressiva na qualidade de vida do ser humano, que o coloca como centro e sujeito principal do desenvolvimento, por meio do crescimento econômico com equidade social, das transformações dos métodos de produção e dos padrões de consumo, sustentando-se no equilíbrio ecológico e no suporte vital de

18 FEATHERSTONE, Mike. $O$ desmanche da cultura: globalização, pósmodernismo e identidade. Tradução Carlos Eugênio Marcondes de Moura. São Paulo. Coleção Megalópolis. Studio Nobel:SESC, 1997. Pp. 161-164.

Universitas - Relações Int., Brasília, v. 2, n.1, p. 103-115, jan./jun. 2004 
sua região. Este processo implica o respeito à diversidade ética e cultural, a nível regional, nacional e local, assim como o fortalecimento e a plena participação cidadã na convivência pacífica e harmônica com a natureza, sem comprometer e garantindo a qualidade de vida das gerações futuras. ${ }^{19}$

Muitos criticam ao progresso e ao embasamento teórico da idéia do desenvolvimento sustentável por crerem que a sua efetivação, tratamento jurídico e implementação não encontram sustento teórico e consensual para concretizar sua viabilidade. Entretanto, já o direito internacional, e, especialmente, os direitos humanos quando trata da proteção internacional dos direitos econômicos, sociais e culturais possui um embasamento teórico e prático que apontam para o êxito da matéria.

Os direitos econômicos, sociais e culturais são aqueles de responsabilidade progressiva do Estado; aqueles que ainda não possuindo uma aplicabilidade imediata fazem pauta da responsabilidade estatal, pois tratam justamente da abnegação dos Estados frente à deterioração das condições de vida de vastos segmentos da população de numerosos países. Atualmente, os maiores esforços neste campo têm sido o de assegurar a exigibilidade e justiciabilidade desses direitos.

A América Latina, na inauguração do século XXI, é atualmente a região com mais desigualdade do Mundo. ${ }^{20}$ Isto influi seriamente para que os logros em crescimento não cheguem aos setores pobres. Tampouco amplos setores da classe média são favorecidos com eles. Enquanto que em sociedades como a Suiça a classe média representa $60 \%$ da população, em diversos países latinoamericanos essa porcentagem é menor que $20 \%$. A desigualdade trava os mecanismos de propagação dos logros econômicos. ${ }^{21}$

\footnotetext{
${ }^{19}$ Este conceito de Desenvolvimento Sustentável foi desenvolvido na "Cumbre Ecológica de Centroamerica para el Desarrollo Sostenible", uma reunião de presidentes da América Central, realizada em Managuá, Nicaraguá, nos dias 12 e 13 de outubro de 1994.

${ }^{20}$ Human Development Report 1999. UNDP. New York. Oxford. Oxford University Press. 1999.

${ }^{21}$ KLIKSBERG, Bernardo. op. citi.
}

Universitas - Relações Int., Brasília, v. 2, n.1, p. 103-115, jan./jun. 2004 
A própria CEPAL concorda que a persistência da pobreza e da rigidez distributiva tem dificultado a constituição na região de sociedades mais integradas. Uma sociedade integrada é aquela em que a população comporta-se segundo modelos socialmente aceitados e em que existe uma convergência das metas culturais, as oportunidades existentes para alcançá-las e a formação de capacidades que permita aos indivíduos aproveitar tais oportunidades. É importante ressaltar que integração social não quer dizer homogeneização. Em uma sociedade moderna deve-se respeitar o direito à identidade cultural própria e valorizar a diversidade. Isto é importante na América Latina e Caribe, onde as sociedades são multiétnicas e pluriculturais. A região não se caracteriza por possuir altos níveis de integração social, em parte devido a frustração derivada da pobreza e do desemprego, o que é particularmente notório nos jovens das zonas urbanas que, apesar de terem um capital educacional superior ao de seus pais, mostram taxas de desempregos maiores. Ademais, encontram-se expostos à informação sobre novos e variados bens e serviços que se constituem em símbolos de mobilidade social, mas em sua maioria não tem acesso a eles. $^{22}$

A desestruturação social da região viu-se afetada pela falta de uma política social agressiva como demandava o crescente vazio social. Os investimentos dos Estados em educação e saúde vêm sendo reduzidos simultaneamente ao fato de que crescia a demanda por educação pública e serviços de saúde estatais. O BID observou que:

"A oferta de serviços viu-se afetada, em quantidade e em qualidade, pela redução do gasto público exigido pelos programas de estabilização, antes que fossem madurados os modelos alternativos para melhorá-los em termos de eficiência, eficácia e eqüidade."23

Somadas as severas dificuldades já existentes para a transformação estrutural dos serviços (inércia burocrática, interesses corporativos, rigidez orçamentária e de normas jurídicas), B. Kliksberg agrega algumas dificuldades adicionais: ${ }^{24}$

22 CEPAL, op. citi., Capítulo VII, Seção D.

${ }^{23}$ BID. Reforma Social y Pobreza, 1993.

${ }^{24}$ KLIKSBERG, Bernardo. op. citi.

Universitas - Relações Int., Brasília, v. 2, n.1, p. 103-115, jan./jun. 2004 
1. o desmantelamento a todos os níveis dos aparatos institucionais e a perda de recursos humanos de alto nível;

2. a persistente debilidade operativa em setores institucionais autônomos, que em muitos casos entravou a efetividade de ensaios de descentralização de responsabilidades;

3. a sociedade civil -incluindo ao setor privado- continua sem ter capacidade suficiente para preencher os vazios deixados pelo Estado na prestação de serviços.

O Diretor da London School of Economics (LSE), uma das mais respeitadas academias de ciências sociais atualmente, Anthony Giddens, conclui categoricamente sobre a globalização:

"Apesar do crescimento econômico e da interdependência cultural, a ordem global está afetada por grandes desigualdades e dividida num mosaico de estados com preocupações comuns e simultaneamente divergentes. Não há, na realidade, qualquer indício de uma convergência política que consiga, num futuro próximo, superar o conflito de interesses entre os vários países. Uma das características mais preocupantes do mundo de hoje é que, apesar da existência das Nações Unidas, a globalização crescente não é acompanhada quer por uma integração política, quer pela redução das desigualdades a nível internacional em termos de riqueza e poder." 25

É, pois, a globalização um fenômeno desenvolvido em prol do capital, construído por e nascido para atender a uma elite mundial individualista. Ela é excludente em si mesma desde sua origem. $\mathrm{O}$ grande pensador húngaro e Professor Emérito da Universidade de Sussex, na Inglaterra, István Mészáros afirma:

"Independentemente das alegações da atual "globalização", é impossível existir universalidade no mundo social sem igualdade substantiva. Evidentemente, portanto, o sistema do capital, em todas as suas formas concebíveis ou historicamente conhecidas, é totalmente incompatível com suas próprias projeções - ainda que distorcidas e estropiadas - de

${ }^{25}$ Giddens, Anthony. Sociologia, Lisboa: Fundação Calouste Gulbenkian, 2002, p. 89.

Universitas - Relações Int., Brasília, v. 2, n.1, p. 103-115, jan./jun. 2004 
universalidade globalizante. E é enormente mais incompatível com a única realização significativa da universalidade viável, capaz de harmonizar o desenvolvimento universal das forças produtivas com o desenvolvimento abrangente das capacidades e potencialidades dos indivíduos sociais livremente associados, baseados em suas aspirações conscientemente perseguidas. A potencialidade da tendência universalizadante do capital, por sua vez, se transforma na realidade da alienação desumanizante e na reificação." 26

O fenômeno da globalização traz consigo, então, a suspeita de que ao início do século XXI o capital é o grande triunfador. Como se não bastasse, alerta para o fato de que a exclusão e a desigualdade sociais vêm acompanhadas pelo distanciamento cada vez maior entre o poder do Estado e a possibilidade da convivência harmônica e pacífica entre as nações, que é o objetivo final do direito internacional e das relações internacionais.

\section{Referências Bibliográficas}

BROWN, S., International Relations in a changing Global Systens. Toward a Theory of Global Systens, Westview Press, Boulder, 1991.

CASSESE, Antonio, Los Derechos Humanos en el Mundo Contemporáneo, Barcelona, Editora Ariel, 1993.

CHOMSKY, Noam, Year 501 - The Conquest Continues, Boston, South End Press, 1993.

DIERCKXSENS, Win, De la Globalización a la Perestroika Occidental, Costa Rica, Editorial DEI, 1994.

DRUCKER, Peter, From Nation State to Megaestate. The Post Capitalist Society, Harper Business, New York, 1993.

FEATHERSTONE, Mike(org.), Cultura Global: Nacionalismo, Globalização e Modernidade, Editora Vozes, $2^{\mathrm{a}}$ Edição, Petrópolis, R.J..

GIDDENS, Anthony. Sociologia, Lisboa: Fundação Calouste Gulbenkian, 2002.

${ }^{26}$ Mészáros, István. O Século XXI: socialismo ou barbárie?, São Paulo: Boitempo Editorial, 2003, p.17.

Universitas - Relações Int., Brasília, v. 2, n.1, p. 103-115, jan./jun. 2004 
HIRST, P. e THOMPSON, G., Globalização em Questão, Editora Vozes, Petrópolis R.J., 1998.

INSTITUTO INTERAMERICANO DE DERECHOS HUMANOS, Serie Estudios Básicos de Derechos Humanos, Costa Rica, IIDH.

MÉSZÁROS, István. O Século XXI: socialismo ou barbárie?, São Paulo: Boitempo Editorial, 2003.

ORDÓÑEZ, J. y VÁSQUEZ, E., Derechos Económicos y Desarrollo en América Latina, San José, IIDH, 1991.

STAVENHAGEN, R. y ITURRALDE, D., Entre la Ley y la Costumbre. El Derecho Consuetudinário Indígena en América Latina. México: III - IIDH, 1990.

VIOTTI, Paul R. \& KAUPPI, Mark V. (orgs.), International Relations Theory: Realism, Pluralism, Globalism. New, Macmillan, 1993, 2. Ed.

Universitas - Relações Int., Brasília, v. 2, n.1, p. 103-115, jan./jun. 2004 